\title{
Developing disaster management and first aid guidelines for school teachers in Cairo Egypt
}

\author{
Fathia Ahmed Mersal , Rasmia Abd-El Sattar Aly \\ Faculty of nursing, Ain Shams University, Cairo, Egypt
}

Received: December 5, 2015

Accepted: January 18, 2016

Online Published: February 17, 2016

DOI: $10.5430 /$ jnep.v6n7p41

URL: http://dx.doi.org/10.5430/jnep.v6n7p41

\begin{abstract}
Background: Each year, schools all over the world suffer from disasters, ranging from small to large damaging disasters that affect children safety and health. Teachers play significant roles in child protection. Therefore, teachers' training is very important for effective school disaster management. Aim: This study aims at evaluating the effectiveness of educational guidelines on school teachers' knowledge and skills regarding disasters and first aid management of school children.

Methods: Quasi-experimental design utilized for conducting the study. Purposive sample of 59 school teachers from Mostafa Kamel preparatory school and Emad Ali Kamel primary school, Cairo Egypt was allocated. Data were collected through demographic data, school teachers' first aid and disaster management knowledge, observation checklist for first aid and disaster management.

Results: The study revealed that, regarding knowledge, $18.6 \%$ of teachers had satisfactory first aid knowledge pre intervention; meanwhile post intervention was $66.1 \%$. For practice, $59.3 \%$ of them gained adequate first aid practice after implementation of program, while pre intervention only $10.2 \%$ of them had. Also $1.7 \%$ of them had satisfactory disaster management knowledge and practice pre intervention, meanwhile post intervention $61 \%$ of teachers got with statistical significant difference pre and post intervention. Positive correlation found $(p>.000)$ among demographic characteristics, school teachers' knowledge and practice of first aid and disaster management.

Conclusions: The study concluded that a disaster management and first-aid training program for school teachers improved their knowledge and practice. Recommendation: Implementation of this program is highly recommended for all school teachers to enhance their knowledge and practice regarding disaster and first aid management. Further research needed to assess the impact of such programs on school health safety and child health.
\end{abstract}

Key Words: Disaster management, First aid, School teachers, Educational guidelines

\section{INTRODUCTION}

Disasters have a significant concern both nationally and internationally pertaining to damages caused by them. Recently, the number of natural and human-made disasters has increased dramatically. ${ }^{[1]}$

According to UNDP 2008, no country that does not stand the threat of a disaster, though they may be threatened at different levels. ${ }^{[2]}$ Disaster is a serious disruption of the function of a community or a society involving widespread human, material, economic or environmental losses and impacts, which exceed the ability of the affected community or society to cope with using its own resources. ${ }^{[3]}$

Children have considered primarily as vulnerable group victims of disasters. ${ }^{[4]}$ In addition, they are vulnerable to injuries

*Correspondence: Fathia Ahmed Mersal; Email: khomarkh@yahoo.com; Address: Faculty of nursing, Ain Shams University, Cairo, Egypt. 
and accidents. Usually, one comes across minor bruises but at times, children may face severe accidents resulting in fractures, bleeding, fainting or even drowning, and thus, first aid becomes as important as taking a child to a medical facility. ${ }^{[5]}$ Children classified as vulnerable groups due to lack of understanding of the situation and lack of sufficient compatibility strategies during disasters. Since $20 \%$ of the victims of the disasters are children and the fact that crises threaten strategic interests, special attention has to pay to preparedness and reducing the disasters' devastating effects. ${ }^{[6]}$

"First aid is the provision of initial care for an illness or injury. It performed by a lay person to a sick or injured patient until definitive medical treatment accessed. Certain self-limited illnesses or minor injuries may not require further medical care past the first aid intervention. It generally consists of a series of simple and, in some cases, potential life-saving techniques that an individual can be trained to perform with minimal equipment.". [7]

First aid training has the potential to reduce morbidity and mortality from common injuries and illnesses, which represent a significant public health burden. In addition, training courses must prepare individuals to provide appropriate and efficacious treatment for a wide range of conditions. ${ }^{[8]}$

School is an important institution for learning students' health. School health services commonly neglected due to lack of awareness and education about common health problems and first aid care. ${ }^{[9]}$ The teachers have the responsibility to keep an eye on their students. They should make sure that they are comfortable and secured within the school building. ${ }^{[10]}$

Children spend most of the time in school under the direct supervision of teachers. They exposed to various types of epidemiological factors in the school, which influence their present and future state of health. ${ }^{[5]}$ School teachers viewed, as being in a position to support students' emotional and behavioral needs during traumatic events. ${ }^{[11]}$ Hence, first aid should wellknown by school teachers to meet the urgent needs of school children during minor injuries. The importance of first-aid measures is particularly evident when the victim is a child. Teacher is the key person in school who attends such type of victims and always in a position to save their lives. Healthy safe environment is very important to avoid these hazards beside qualified teachers who can detect any health problem and can give first aid for commonly occurring emergencies in schools. ${ }^{[5]}$

Provide Health education programs in schools is eligible to prevent health related problems, which participate in children and community's wellness. ${ }^{[12,13]}$ First aid health education programs in schools are essential. Performing first aid actions requires a person's active and responsible participation based on the ability of taking the right decisions. Health education in first aid supports such ability, providing knowledge and skills, and enhancing people's ability to take correct actions. The immediate response in a health emergency can limit undesirable outcomes or even save lives. ${ }^{[14]}$

Teacher training is significant for effective school disaster management. When considering school disaster management, it is clear that schoolteachers play significant roles. In 2014, Shiwaku pointed out teacher training as an important issue particularly in the protection of health and safety of school children. Researches on teacher training for school disaster management are not many. Nevertheless, researches with topics of teacher training for school disaster management contribute to safety in disaster-prone areas. ${ }^{[15]}$

\subsection{Significance of the problem}

Each year, schools all over the world suffer from disasters ranging from small to large damaging disasters that seriously affect the operation of the school. ${ }^{[16]}$ Hence, the teachertraining programs for disaster prevention are necessary. The focal points of disaster prevention education should emphasize knowledge of disaster awareness, attitude toward disaster prevention, disaster preparedness, and proper emergency response. ${ }^{[17]}$

In Egypt, the annual incidence of unintentional injuries sustained by children aged eleven and under estimated as $19.6 \%$ of students in normal school life. ${ }^{[18]}$ Health Insurance Agency in 2009 stated that during school hours approximately 13,000 injuries occurring in school playgrounds yearly in Egyptian schools. ${ }^{[19]}$ In 2014, Torrents caused a great damage inside schools especially in South of Delta Governorates of Asuit, Aswan, Sohag and Kana. Disaster caused in closing schools for week and death of seven students inside their schools because of torrents in different accidents. ${ }^{[20]}$ Egyptian Afack newspaper in 2014 reported that explosion in a preparatory school's laboratory caused 25 injured cases among students. ${ }^{[21]}$

Hegazy et al. (2014) stated that Egyptian schools had no proper disaster management plan and untrained disaster team in primary governmental schools. ${ }^{[22]}$ This may be lead to doubled or tripled cases of victims and injuries among these vulnerable groups. Disaster plan is just a documented paper to accomplish the disaster file in the school. In Egypt, despite unsafe school environment, there are no preparations for school disasters, there is no training for students or their teachers and there is no disaster team. 


\subsection{Aim of the study}

This study aims at evaluating the effectiveness of educational guidelines on schoolteachers' knowledge and skills regarding disaster and first aid management for school children. This aim achieved through the followings:

- Assessing knowledge and skills of disaster management among schoolteachers.

- Assessing knowledge and skills of first aid among school teachers.

- Evaluating the effectiveness of educational guidelines program on disaster and first aid management among school teachers.

\subsection{Hypothesis}

Two hypotheses were developed and tested at 0.05 level of significance.

H0.1 There will be no significant difference between the pretest and posttest knowledge score of school teachers on disaster and first aid management.

H0.2 There will be no significant difference between the pretest and posttest practice score of school teachers on disaster and first aid management.

\section{SUBJECT AND METHODS}

\subsection{Research design}

A quasi-experimental study with pre and post evaluation design utilized to accomplish this study.

\subsection{Settings}

The study was conducted at Mostafa Kamel preparatory school for boys 33 Nubar street, opposite Ministry of Interior, Cairo, Egypt and Emad Ali Kamel primary school 3 Abd el-Azim Corridor of Ramses street Abbaseya. The two schools follow the Western District Directorate of Education, Cairo Governorate, Egypt.

\subsection{Study subjects}

By applying non-probability purposive sampling technique, 59 school teachers were selected for the study, 38 were in Mostafa Kamel preparatory school and 21 were in Emad Ali kamel primary school.

The sample size was calculated by using the Epi Info v.6 software package published by CDC (Centers for Disease Control and Prevention, Atlanta, GA, USA). To find any progress in school teachers' knowledge or skill from an expected level of $30 \%$ or less before the implementation, to $60 \%$ or higher after the implementation, to achieve $80 \%$ power with a medium effect and an alpha of 0.05. A sample size was calculated and a required sample of 50 was determined which was increased to 65 to compensate for the expected 5\% dropout, whereas only 59 teachers completed the questionnaires and accept to participate in the study.

\subsection{Inclusion criteria}

School teachers working in the selected study settings, available during the period of the study, and willing to participate in the study were included.

\subsection{Tools for data collection}

Two different tools were used to collect data for this study. They were developed by researchers in Arabic language based on recent literatures. Tools tested for content validity by agreement of five experts in the fields of Community Health Nursing and Pediatrics to ascertain relevance and completeness.

Tool I: Self-Administered Structured Questionnaire It was developed by the researchers in Arabic language. It contains three parts:

A) Basic information and demographic characteristics of teachers such as age, sex, marital status, job nature, years of experience $e t c$.

B) School teachers' first aid knowledge: It was developed by the researchers in Arabic language based on recent literature and it consists of 55 items to assess general information of first aid management for wound care, burns, fractures, epistaxis, fainting, and foreign bodies in the ear, nose, or eye. The score one given for each correct answer and zero for incorrect answer. The total knowledge considered satisfactory if the percent score reached $60 \%$ or more. Reliability test was done whereas Cronbach's Alpha equals 0.96.

C) School teachers' disaster management knowledge: This was developed by the researchers in Arabic language based on recent literature and it consists of 39 items to assess general information of disaster, disaster preparedness, disaster management, dealing with injured personnel, and impacts of disaster in schools. The score one was given for each correct answer and zero for incorrect answer. The total knowledge considered satisfactory if the percent score reached $60 \%$ or more. Reliability test was done whereas Cronbach's Alpha equal 0.78

Tool II: It was developed and filled by the researchers. It contains two parts:

A) Observation check list for first aid management developed and filled by researchers to assess the skills of teachers in first aid management based on recent literature. It consists of 66 items to assess first aid of wound, burns, fractures, epistaxis, fainting, and foreign bodies in the ear, nose, or eye. 
If the performance was correct the participant scores one, and if incorrect or not done the participant scores zero. A teacher's performance considered adequate if the total score of checklist was $60 \%$ or above. Reliability test was done whereas Cronbach's Alpha equals 0.83.

B) Observation checklist for disaster management developed and filled by researchers to assess the performance of teachers regarding disaster management based on recent literature. It consists of 35 items to assess disaster team management, communication skills during disaster, evacuation plan, schools' reactions to disasters, and dealing with injured personnel. If the performance was correct the participant scores one, and if incorrect or not done he or she scores zero. Teacher's performance considered adequate if the total score of checklist was $60 \%$ or more. Reliability test were done whereas Cronbach's Alpha equals 0.74.

\subsection{Ethical consideration}

Ethical approval from Ain Shams University ethics committee obtained, together with an approval from the Research Center of the Faculty of Nursing. Afterwards, an official permission from the Cairo Educational Directorate and administrators of the two selected schools to conduct the proposed study elicited. Meetings and discussions were held between the researchers and schools administrators to make them aware about the purpose of the study, as well as to get better cooperation during the implementation phase. It was important to have their full support, especially to find out some sort of motivation to stimulate school teachers to participate positively in the study. The aim of the research was explained to the participants. After clarifying the procedures of the study, a verbal consent from every school teacher to participate in the study was obtained. Participants were informed about their right to refuse participation and to withdraw at any time without giving reasons and with no consequences. Total confidentiality of any given information assured.

\subsection{Pilot study}

The pilot study commenced once ethical approval had obtained. A pilot study carried out by $10 \%$ of school personnel (4 school personnel) to test the clarity, applicability, objectivity and feasibility of the tools to conduct the study. No Changes or modifications were done. The school teachers who were included in the pilot study were included in the study.

\subsection{Procedures of the study}

This study conducted through four consecutive phases: assessment, planning, implementation and evaluation. Data collection was done pre and post guidelines implementation.

\section{I-Assessment phase}

The researchers started with a pilot test, and then validated the tool through the opinions of experts in nursing. Then the data collected from teachers under the study to identify their knowledge and skills regarding first aid and disaster management at schools.

\section{II-Planning phase}

Based on the assessment phase, the program content and media (in the form of the program booklet, posters, and visual materials as video clips and pictures) were prepared by the researchers for school teachers under the study based on their learning gaps and needs identified from the pre-intervention assessment.

\section{III-Implementation phase}

Implementation of the program done with the school teachers after explanation of the purpose of the study and their acceptance of participation. Teachers were divided into 8 groups; each group included seven teachers to facilitate training program application. They attended the educational program for 12 sessions/month). The program took 3 sessions/week/one month. Every session took about 20-30 minutes followed by 15 minutes for discussion.

The collection of data and application of the program lasted over a period of six months, started from November 2014 and ended in April 2015. Data were collected in three days/week from 9 am to $12 \mathrm{md}$ according the school visiting hours and the presence of the targeted school personnel.

Individual sessions, group discussions, demonstrations and re-demonstrations used as teaching methods. Audio-visual aids as video clips, role-plays and introduction of a booklet were used to facilitate the process of educational programto serve the purposes for which it designed.

All teachers and administrators provided with a booklet on first aid and disaster management practice as well as a copy of all teaching materials on a CD at the end of data collection.

The researchers' telephone numbers given to school personnel and telephone numbers of all participating teachers taken to ensure contact probabilities and to facilitate meeting them during follow up visits in each school in order to complete data collection during follow up period.

\section{IV-Evaluation phase}

The evaluation phase emphasized on estimating the effect of the educational guideline on school teachers' knowledge and practice of first aid and disaster management. The post-tests conducted for studied teachers after two weeks of implementation phase. 


\subsection{Statistical design}

The quantitative data were analyzed using Statistical Package for Social Sciences (SPSS) program version 16. Data were presented in tables and charts using actual numbers and percentages. Appropriate statistical methods were applied (percentage, chi-square $\left(\chi^{2}\right)$, correlation coefficient $(r), t$-test. Regarding $p$ value, it was considered that: non-significant (NS) if $p>.05$, Significant (S) if $p<.05$, Highly Significant (HS) if $p<.01$.

\section{RESULTS}

Regarding demographic characteristics, Table 1 shows that more than two-fifths $(44.1 \%)$ of the school teachers aged 40 years and more, $(44.37 \pm 7.83)$ were mean and standard deviation of them. It shows that more than half of them $(55.9 \%)$ were males, nearly three quarters $(71.2 \%)$ were married, majority (93.2\%) were teachers, nearly half $(50.9 \%)$ had experience more than 20 years and more than two thirds $(67.8 \%)$ were not trained on first aid. In addition, it shows that nearly two-thirds of them worked in school Mostafa Kamel preparatory school.

Regarding first aid knowledge of school teachers pre and post intervention, Table 2 shows that nearly two thirds (62.7\%) had unsatisfactory knowledge related to first aid of epistaxis, nearly three quarters $(76.3 \%$ and $79.7 \%$ ) had unsatisfactory knowledge related to general information about first aid and first aid of burn respectively. In addition, it shows that most of them $(84.7 \%, 91.5 \%, 84.7 \%, 91.5 \%, 86.4 \%)$ had unsatisfactory knowledge related to first aid of wounds, fractures, fainting, foreign bodies, bites and stings respectively. While after implementation, school teachers had satisfactory knowledge with high statistical significant difference pre and post intervention. Moreover, it shows that the means of total first aid knowledge pre and post intervention were $17.40 \pm 15.35$ and $39.40 \pm 11.61$ respectively $(p>.000)$.

Regarding difference in total first aid knowledge among schoolteachers in pre and post intervention, Figure 1 illustrates the improvement in their first aid knowledge after implementation of program. Whereas pre intervention schoolteacher is satisfactory knowledge were $18.6 \%$, post intervention were $66.1 \%$.

Regarding first aid practice of school teachers pre and post intervention, Table 3 illustrates that most of them $(86.4 \%$, $83.1 \%, 89.8 \%$ and $83.1 \%$ ) had inadequate practice related to first aid of wounds, fractures, bites and fainting respectively. Nearly three quarters $(78 \%)$ had inadequate practice related to first aid of epistaxis. In addition, it shows that the majority of them (94.9\% and $91.5 \%$ ) had inadequate practice related to first aid of foreign bodies and burns respectively.
Meanwhile after implementation school teachers acquired good first aid practice with statistical significant difference pre and post intervention. Moreover, it shows that the means of total first aid practice pre and post intervention were 10.09 \pm 11.14 and $42.25 \pm 9.1$ respectively with highly statistical significant difference pre and post intervention $(p>.000)$.

Regarding difference in total first aid, practice among school teachers pre and post intervention, Figure 2 shows that $59.3 \%$ of them acquired adequate practice regarding first aid after implementation of program, but pre intervention it was only $10.2 \%$.

Table 1. Number and percent distribution of schoolteachers according to their demographic characteristics

\begin{tabular}{|c|c|c|}
\hline Parameter & $\mathrm{N}=59$ & $\%$ \\
\hline \multicolumn{3}{|l|}{ Age } \\
\hline $30-$ & 18 & 30.5 \\
\hline $40-$ & 26 & 44.1 \\
\hline $50-$ & 15 & 25.4 \\
\hline Mean of age & $44.37 \pm 7.83$ & \\
\hline \multicolumn{3}{|l|}{ Gender } \\
\hline Male & 33 & 55.9 \\
\hline Female & 26 & 44.1 \\
\hline \multicolumn{3}{|l|}{ Marital status } \\
\hline Single & 6 & 10.2 \\
\hline Married & 42 & 71.2 \\
\hline Divorced and widow & 11 & 18.7 \\
\hline \multicolumn{3}{|l|}{ Job type } \\
\hline School manager & 2 & 3.4 \\
\hline Vice-manager & 2 & 3.4 \\
\hline Teacher & 55 & 93.2 \\
\hline \multicolumn{3}{|l|}{ Experience } \\
\hline$>10$ & 13 & 22 \\
\hline $10-$ & 16 & 27.1 \\
\hline 20- & 30 & 50.9 \\
\hline Mean of Experience & $18.86 \pm 9.52$ & \\
\hline \multicolumn{3}{|l|}{ Previous training } \\
\hline Yes & 19 & 32.2 \\
\hline No & 40 & 67.8 \\
\hline \multicolumn{3}{|l|}{ School Name } \\
\hline Mostafa Kamel preparatory school & 38 & 64.4 \\
\hline Emad Ali Kamel primary school & 21 & 35.6 \\
\hline
\end{tabular}

Regarding disaster knowledge of school teachers pre and post intervention, Table 4 demonstrates that nearly three quarters $(74.6 \%, 79.7 \%$ and $79.7 \%)$ had unsatisfactory knowledge related to general information about disaster, disaster preparedness and dealing with injured personnel respectively. Also it shows that most of them $(89.8 \%)$ had unsatisfactory knowledge related to impact of disaster in schools and all of them had unsatisfactory knowledge related to disaster management, while after implementation, school teachers 
had satisfactory knowledge with highly statistical significant $\quad$ and post intervention were $(13.03 \pm 4.75$ and $23.03 \pm 3.15)$ difference pre and post intervention. Moreover, it shows respectively $(p>.000)$. that the means of total disaster management knowledge pre

Table 2. First aid knowledge difference for schoolteachers' pre and post-intervention phase

\begin{tabular}{|c|c|c|c|c|c|c|}
\hline \multirow{2}{*}{ Item } & \multicolumn{2}{|c|}{ Pre intervention $($ Total $=59)$} & \multicolumn{2}{|c|}{ Post intervention $($ Total $=59)$} & \multirow{2}{*}{$\chi^{2}$} & \multirow{2}{*}{$p$-value } \\
\hline & No. & $\%$ & No. & $\%$ & & \\
\hline \multicolumn{7}{|c|}{ General information about first aid } \\
\hline Satisfactory & 14 & 23.7 & 44 & 74.6 & \multirow[t]{2}{*}{30.51} & \multirow[t]{2}{*}{.000} \\
\hline Unsatisfactory & 45 & 76.3 & 15 & 25.4 & & \\
\hline \multicolumn{7}{|c|}{ First aid of wound and injury } \\
\hline Satisfactory & 9 & 15.3 & 37 & 62.7 & \multirow[t]{2}{*}{27.93} & \multirow[t]{2}{*}{.000} \\
\hline Unsatisfactory & 50 & 84.7 & 22 & 37.3 & & \\
\hline \multicolumn{7}{|l|}{ First aid of fractures } \\
\hline Satisfactory & 5 & 8.5 & 36 & 61 & \multirow[t]{2}{*}{35.92} & \multirow[t]{2}{*}{.000} \\
\hline Unsatisfactory & 54 & 91.5 & 23 & 39 & & \\
\hline \multicolumn{7}{|l|}{ First aid of epistaxis } \\
\hline Satisfactory & 22 & 37.3 & 41 & 69.5 & \multirow[t]{2}{*}{12.29} & \multirow[t]{2}{*}{.001} \\
\hline Unsatisfactory & 37 & 62.7 & 18 & 30.5 & & \\
\hline \multicolumn{5}{|c|}{ First aid of foreign bodies in ear, nose, and eye } & \multirow{3}{*}{37.85} & \multirow{3}{*}{.000} \\
\hline Satisfactory & 5 & 8.5 & 37 & 62.7 & & \\
\hline Unsatisfactory & 54 & 91.5 & 22 & 37.3 & & \\
\hline \multicolumn{7}{|l|}{ First aid of bites and stings } \\
\hline Satisfactory & 8 & 13.6 & 38 & 64.4 & \multirow[t]{2}{*}{33.98} & \multirow[t]{2}{*}{.000} \\
\hline Unsatisfactory & 51 & 86.4 & 21 & 35.6 & & \\
\hline \multicolumn{7}{|l|}{ First aid of Burn } \\
\hline Satisfactory & 12 & 20.3 & 37 & 62.7 & \multirow[t]{2}{*}{21.81} & \multirow[t]{2}{*}{.000} \\
\hline Unsatisfactory & 47 & 79.7 & 22 & 37.3 & & \\
\hline \multicolumn{7}{|l|}{ First aid of Fainting } \\
\hline Satisfactory & 9 & 15.3 & 51 & 86.4 & \multirow[t]{2}{*}{59.81} & \multirow[t]{2}{*}{.000} \\
\hline Unsatisfactory & 50 & 84.7 & 8 & 13.6 & & \\
\hline Score of total knowledge & 17.4 & & 39.4 & & $\begin{array}{l}T \text { test } \\
-19.41\end{array}$ & .000 \\
\hline
\end{tabular}

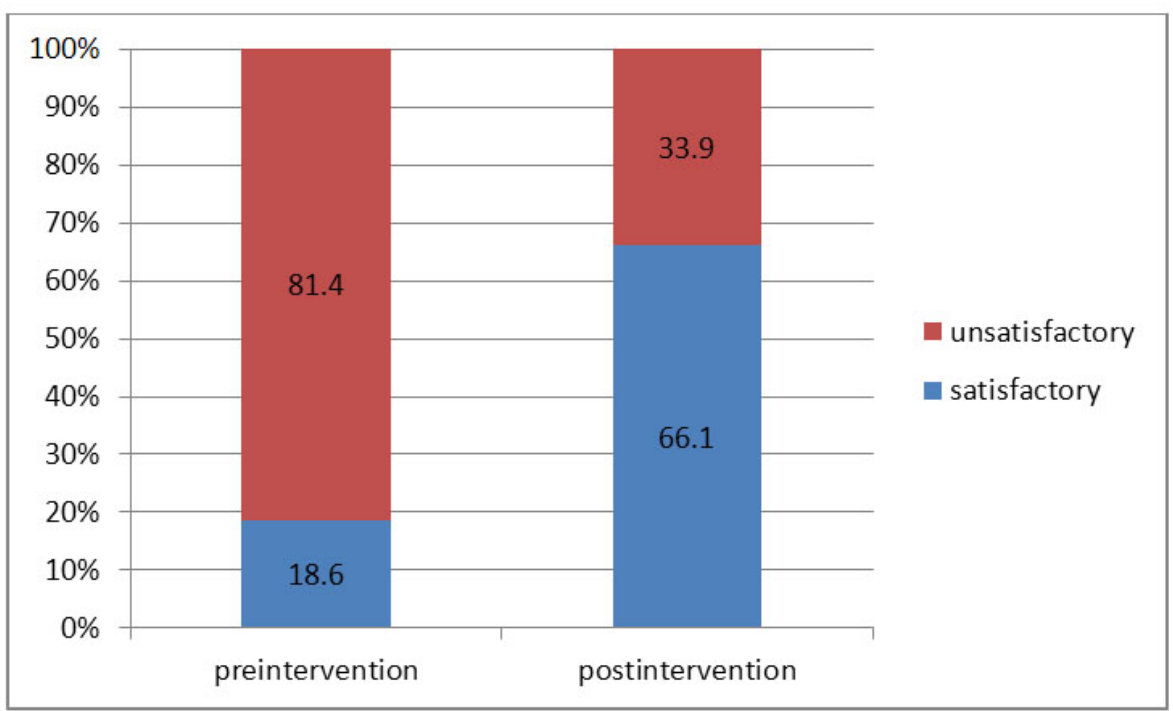

Figure 1. Total knowledge of first aid of schoolteachers'pre and post intervention 
Table 3. First aid practice difference for schoolteachers' pre and post-intervention phase

\begin{tabular}{|c|c|c|c|c|c|c|}
\hline \multirow{2}{*}{ Item } & \multicolumn{2}{|c|}{ Pre intervention $($ Total $=59)$} & \multicolumn{2}{|c|}{ Post intervention $($ Total $=59)$} & \multirow{2}{*}{$\chi^{2}$} & \multirow{2}{*}{$p$-value } \\
\hline & No. & $\%$ & No. & $\%$ & & \\
\hline \multicolumn{7}{|c|}{ First aid of wound and injury } \\
\hline Adequate & 8 & 13.6 & 44 & 74.6 & 44.55 & .000 \\
\hline Inadequate & 51 & 86.4 & 15 & 25.4 & & \\
\hline \multicolumn{7}{|l|}{ First aid of fractures } \\
\hline Adequate & 10 & 16.9 & 37 & 62.7 & 25.77 & .000 \\
\hline Inadequate & 49 & 83.1 & 22 & 37.3 & & \\
\hline \multicolumn{7}{|l|}{ First aid of epistaxis } \\
\hline Adequate & 13 & 22 & 51 & 86.4 & 49.30 & .000 \\
\hline Inadequate & 46 & 78 & 8 & 13.6 & & \\
\hline \multicolumn{7}{|c|}{ First aid of foreign bodies in ear, nose, and eye } \\
\hline Adequate & 3 & 5.1 & 35 & 59.3 & 39.74 & .000 \\
\hline Inadequate & 56 & 94.9 & 24 & 40.7 & & \\
\hline \multicolumn{7}{|c|}{ First aid of bites and stings } \\
\hline Adequate & 6 & 10.2 & 37 & 62.7 & 35.16 & .000 \\
\hline Inadequate & 53 & 89.8 & 22 & 37.3 & & \\
\hline \multicolumn{7}{|l|}{ First aid of Burn } \\
\hline Adequate & 5 & 8.5 & 35 & 59.3 & 34.03 & .000 \\
\hline Inadequate & 54 & 91.5 & 24 & 40.7 & & \\
\hline \multicolumn{7}{|l|}{ First aid of Fainting } \\
\hline Adequate & 10 & 16.9 & 50 & 84.7 & 54.25 & .000 \\
\hline Inadequate & 49 & 83.1 & 9 & 15.3 & & \\
\hline Score of total practice & 10.0 & & 42.2 & & $\begin{array}{l}t \text {-test } \\
-34.66\end{array}$ & .000 \\
\hline
\end{tabular}

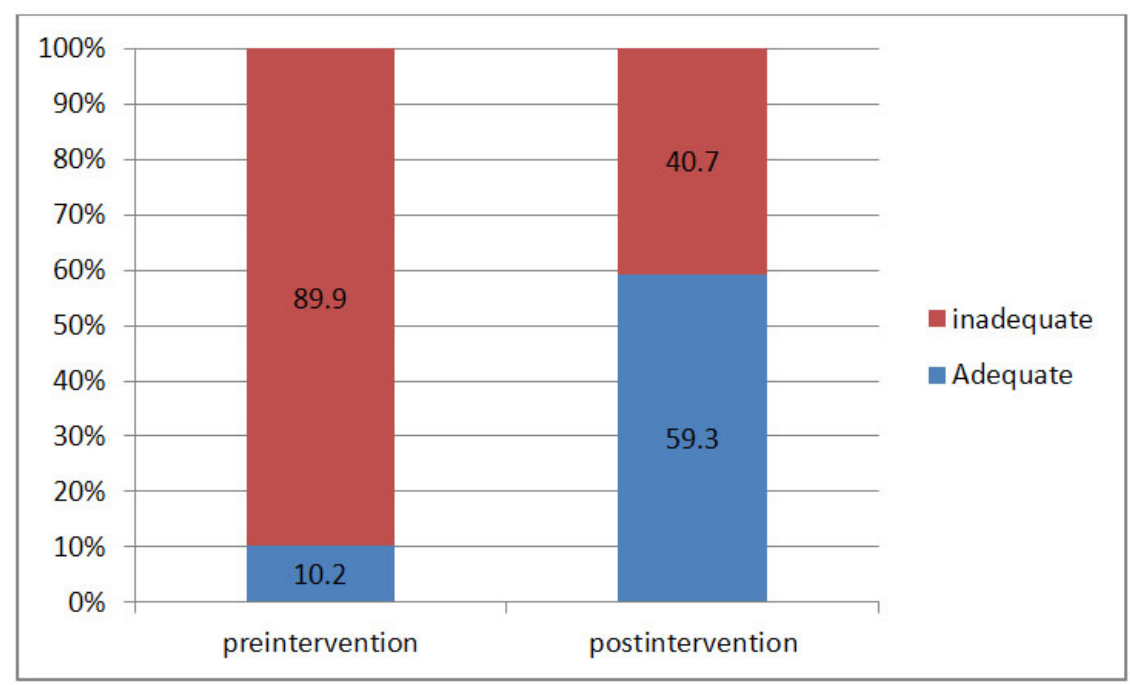

Figure 2. Total practice of first aid of schoolteachers in pre and post intervention

Regarding difference in total knowledge of disaster man- ment knowledge after implementation of program. Whereas agement among school teachers' pre and post intervention, pre intervention schoolteacher is satisfactory knowledge was Figure 3 illustrates improvement in their disaster manage- $1.7 \%$, post intervention was $61 \%$. 
Table 4. Disaster knowledge difference for schoolteachers' pre and post-intervention phase

\begin{tabular}{|c|c|c|c|c|c|c|}
\hline \multirow{2}{*}{ Item } & \multicolumn{2}{|c|}{ Pre intervention $($ Total $=59)$} & \multicolumn{2}{|c|}{ Post intervention $($ Total $=59)$} & \multirow{2}{*}{$\chi^{2}$} & \multirow{2}{*}{$p$-value } \\
\hline & No. & $\%$ & No. & $\%$ & & \\
\hline \multicolumn{7}{|c|}{ General information about disaster } \\
\hline Satisfactory & 15 & 25.4 & 34 & 57.6 & 12.59 & .000 \\
\hline Unsatisfactory & 45 & 74.6 & 25 & 42.4 & & \\
\hline \multicolumn{7}{|l|}{ Disaster preparedness } \\
\hline Satisfactory & 12 & 20.3 & 36 & 61 & 20.22 & .000 \\
\hline Unsatisfactory & 47 & 79.7 & 23 & 39 & & \\
\hline \multicolumn{7}{|l|}{ Disaster Management } \\
\hline Satisfactory & 0 & 0 & 38 & 64.4 & 56.05 & .000 \\
\hline Unsatisfactory & 59 & 100 & 21 & 35.6 & & \\
\hline \multicolumn{7}{|c|}{ Dealing with injured personnel } \\
\hline Satisfactory & 12 & 20.3 & 39 & 66.1 & 25.17 & .000 \\
\hline Unsatisfactory & 47 & 79.9 & 20 & 33.9 & & \\
\hline \multicolumn{7}{|c|}{ Impacts of disaster in Schools } \\
\hline Satisfactory & 6 & 10.2 & 48 & 81.4 & 60.22 & .000 \\
\hline Unsatisfactory & 53 & 89.8 & 11 & 18.6 & & \\
\hline Score of total knowledge & 13.0 & & 23.0 & & $\begin{array}{l}t \text {-test } \\
-21.05\end{array}$ & .000 \\
\hline
\end{tabular}

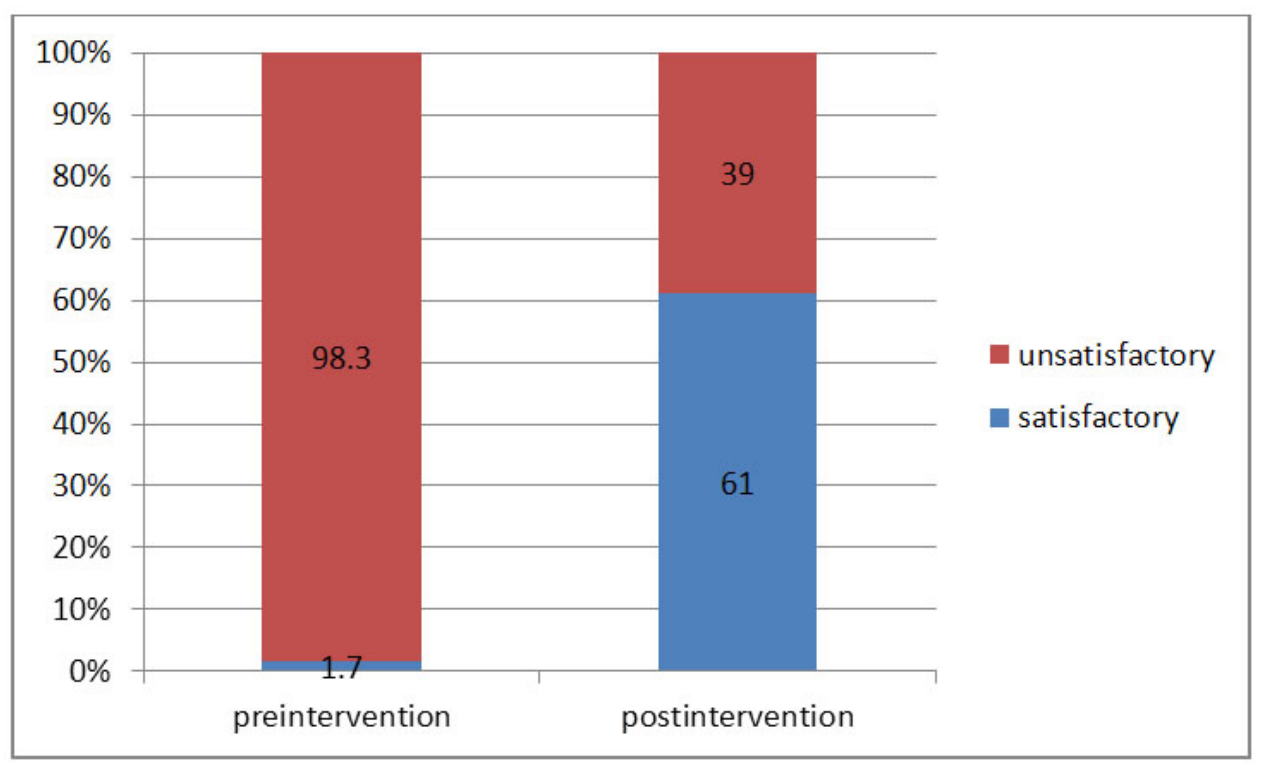

Figure 3. Total knowledge of disaster management of schoolteachers' pre and post intervention

Regarding disaster management practice of school teachers' pre and post intervention, Table 5 illustrates that only minority of them $(3.4 \%)$ had adequate practice. Meanwhile after implementation nearly two-thirds $(66.1 \%)$ of school teachers acquired adequate practice with highly statistical significant difference pre and post intervention. Moreover, it shows that the means of total disaster management practice pre and post intervention were $(4.32 \pm 4.13$ and $19.93 \pm$
4.44) respectively with statistical significant difference pre and post intervention $(p>.000)$.

Regarding relation between socio demographic variable of school teachers and their knowledge and practice of first aid, Table 6 shows positive correlation $(p>.000)$ between age, previous training and experience of them and between their knowledge and practice of first aid. This means that the older, the more experienced and the more trained teachers were the 
more knowledgeable and skillful they were regarding first were more knowledgeable and skillful than males regarding aid. Additionally, it shows negative correlation $(p>.000)$ first aid.

among school teachers regarding their gender, as females

Table 5. Disaster management practice difference for schoolteachers' pre and post-intervention phase

\begin{tabular}{|c|c|c|c|c|c|c|}
\hline \multirow{2}{*}{ Item } & \multicolumn{2}{|c|}{ Pre intervention $($ Total $=59)$} & \multicolumn{2}{|c|}{ Post intervention $($ Total $=59)$} & \multirow{2}{*}{$\chi^{2}$} & \multirow{2}{*}{ p-value } \\
\hline & No. & $\%$ & No. & $\%$ & & \\
\hline \multicolumn{7}{|l|}{ Total practice } \\
\hline Adequate & 2 & 3.4 & 39 & 66.1 & 51.16 & .000 \\
\hline Inadequate & 57 & 96.6 & 20 & 33.9 & & \\
\hline Score of total practice & \multicolumn{2}{|c|}{$4.32 \pm 4.13$} & \multicolumn{2}{|c|}{$19.93 \pm 4.44$} & & \\
\hline
\end{tabular}

Table 6. Correlation between socio demographic variable of schoolteachers regarding their knowledge and practice of first aid before intervention

\begin{tabular}{|c|c|c|c|c|}
\hline \multirow{2}{*}{ Items } & \multicolumn{2}{|c|}{ Total mean of knowledge } & \multicolumn{2}{|c|}{ Total mean of practice } \\
\hline & $\boldsymbol{R}$ & $p$ value & $\boldsymbol{R}$ & $p$ value \\
\hline Mean of Age & $0.494 * *$ & .000 & $0.559 * *$ & .000 \\
\hline Gender & $-0.356^{* *}$ & .006 & $-0.444 * *$ & .000 \\
\hline Social status & -0.004 & .978 & 0.009 & .943 \\
\hline Mean of Experience & $0.449 * *$ & .000 & $0.528 * *$ & .000 \\
\hline Job type & $-0.301 *$ & .021 & -0.186 & .157 \\
\hline School name & -0.223 & .090 & -0.133 & .316 \\
\hline Previous training & $0.771^{* *}$ & .000 & $0.787 * *$ & .000 \\
\hline
\end{tabular}

** Correlation is significant at the 0.01 level (2-tailed); * Correlation is significant at the 0.05 level (2-tailed).

Regarding relation between socio demographic variable of school teachers and their knowledge and practice of disaster management, Table 7 shows positive correlation between age, previous training and experience of teachers and betweentheir knowledge and practice of disaster management. This means that the older, the more experienced and the more trained teachers were the more knowledgeable and skillful they were regarding disaster management. Additionally, it shows negative correlation among schoolteachers regarding their gender, as females were more knowledgeable and skillful than males regarding disaster management.

Regarding relation between knowledge and practice of first aid management and disaster management, Table 8 reveals positive correlation between knowledge of first aid, practice of first aid and between knowledge of disaster management which means that knowledge of disaster management correlates positively with practice of disaster management and knowledge and practice of first aid.

Table 7. Correlation between socio demographic variable of schoolteachers regarding their knowledge and practice of disaster management before intervention

\begin{tabular}{lllllc}
\hline \multirow{2}{*}{ Items } & \multicolumn{2}{l}{ Total mean of disaster management knowledge } & & \multicolumn{2}{c}{ Total mean of disaster management practice } \\
\cline { 2 - 3 } Mean of Age & $\boldsymbol{R}$ & $\boldsymbol{p}$ value & .000 & $0.259^{*}$ & \multicolumn{2}{c}{$\boldsymbol{p}$ value } \\
Gender & $0.485^{* *}$ & .003 & $-0.278^{*}$ & .048 \\
Social & $-0.383^{* *}$ & .783 & 0.023 & .862 \\
Mean of Experience & $0.450^{* *}$ & .000 & $0.275^{*}$ & .035 \\
Job type & -0.037 & .122 & -0.023 & .866 \\
School & -0.185 & .160 & 0.002 & .988 \\
Previous training & $0.687^{* *}$ & .000 & $0.273^{*}$ & .036 \\
\hline
\end{tabular}

** Correlation is significant at the 0.01 level (2-tailed); * Correlation is significant at the 0.05 level (2-tailed). 


\section{Discussion}

Egypt has been, and continues to be, susceptible to a multiplicity of natural and man-made disasters. Moreover, urban disasters and severe accidents are also frequent in the country and quite often result in massive disaster situations. ${ }^{[23]}$

Teachers are the main caregivers and the first line of pro- tection for school children. Their role complements that of parents. During school hours, school teachers are actually the first-respondents in cases of disasters or emergencies. They must be able to deal properly with health emergencies both in normal children, and in children with special health care needs. $^{[24]}$

Table 8. Correlation between knowledge and practice of schoolteachers regarding first aid and disaster management before intervention

\begin{tabular}{llllll}
\hline Items & & $\mathbf{( 1 )}$ & $\mathbf{( 2 )}$ & $\mathbf{( 3 )}$ & $\mathbf{( 4 )}$ \\
\hline (1) Mean of Knowledge of first aid & $r$ & 1 & $0.847^{* *}$ & $0.812^{* *}$ & 0.202 \\
& $p$ & & .000 & .000 & .124 \\
(2) Mean of practice of first aid & $r$ & $0.847^{* *}$ & 1 & $0.850^{* *}$ & $0.397^{* *}$ \\
& $p$ & .000 & & .000 & .002 \\
(3) Mean of Knowledge of disaster management & $r$ & $0.812^{* *}$ & $0.850^{* *}$ & 1 & $0.411^{* *}$ \\
& $p$ & .000 & .000 & & .001 \\
(4) Mean of Knowledge of disaster management & $r$ & 0.202 & $0.397^{* *}$ & $.411^{* *}$ & 1 \\
& $p$ & .124 & .002 & .001 & \\
\hline
\end{tabular}

** Correlation is significant at the 0.01 level (2-tailed).

The primary aim of this study was to determine the effectiveness of educational guidelines on school teachers' knowledge and skills regarding disaster and first aids management of school children.

Concerning personal characteristics, it was found that more than two thirds were not trained on first aid. Abernethy et al. in 2003 in USA reported that few schools had performed firstaid training for their teachers, whereas in many other schools none of staff members had updated the first aid training. ${ }^{[25]}$

In addition, Younis and El-Abassy in 2015 conducted a study on primary teachers' first aid management of children's school day accidents stated that the highest percentage of the schoolteachers did not attend any training courses. ${ }^{[26]}$ Therefore, it is very important to conduct education programs for keeping the schoolteachers informed and trained. In addition trained health professionals must carry out these programs at regular intervals. All schoolteachers must learn basic first aid training during a disaster.

The present study declared that the highest percentage of school teachers had incorrect knowledge of first aid management. Most of them had unsatisfactory knowledge related to first aid. Meanwhile, after implementation school teachers acquire satisfactory knowledge with high statistical significant difference pre and post intervention. These findings may be explained by lack of training programs on first aid management and emphasize the importance of providing training on first aid for school teachers.
Most of the time first aid given by lay people such as teachers hence, their knowledge of emergency management of injured students is critical for lives saving especially during disaster. Unfortunately, many studies have reported lack of knowledge of schoolteachers regarding first aid.

In the same line, findings were proved by Ali et al. in 2010 who declared that educational training program on first aid for newly graduated nursery school teachers at Zagazig city had improved the knowledge and skills of nursery school teachers in first aid and dealing with wounds, fainting, burns, epistaxis, epileptic fits, and fractures. This improvement proved statistically. ${ }^{[27]}$

Also Baser et al. in 2007 conducted a study on Turkish teachers to evaluate the knowledge of first aid among primary school teachers. They stated that most of the teachers did not have knowledge about first aid. ${ }^{[28]}$ Similarly, Li et al. in 2014 conducted a study on effects of pediatric first aid training on pre school teachers. Their results demonstrated that the training significantly improves knowledge levels toward first aid among respondents who attended the training course. ${ }^{[29]}$

Regarding first aid skills, the present study results revealed that many incorrect practices were prevalent among respondents and the most of them had inadequate performance related to first aid. Meanwhile after implementation school teachers acquired good first aid practices with statistical significant difference pre and post intervention. Unfortunately, life-threatening emergencies can occur in any school, at any 
time. So teacher should be skillful in first aid measures to save lives by recognizing life-threatening emergencies during disaster and emergency situations.

These findings highlight the importance of the practical training component. Hence, it seems that there is an urgent requirement to strengthen school health services through involving teachers and educators, collaborating with them, and providing them with training programs.

In recent study conducted by Al-Samghan, et al. in 2015 to measure primary school teachers' knowledge about first-aid, they reported that nearly one quarter of primary school teachers in Abha, KSA had previous training in first aid and less than two thirds of them stated that these training included practical exercise. ${ }^{[24]}$ This reflects deficient interest among teachers toward the importance of receiving training on first aid. The findings highlight the lack of the practical training component in more than one third of the attended courses.

Additionally, Abdella, et al. in 2015 conducted a study to evaluate an intervention program for the kindergarten teachers about pediatric first aids through which it was noted that before the program; almost all teachers had unsatisfactory skills. In comparison, more than half of them had satisfactory skills immediately post and during following up of the program intervention with statistical significance difference. ${ }^{[30]}$

Regarding disaster management, the present study demonstrated that high percentage of teachers had poor knowledge related to disaster management, impact of disaster, general information about disaster, disaster preparedness and dealing with injured personnel. There was a high significant improvement in post intervention, which proved by enhancing the means of total disaster management knowledge post intervention $(p>.000)$.

These findings were in accordance with Ramya' study, which conducted in 2006 to assess the effectiveness of a structured teaching program on knowledge regarding rural disaster management among school teachers. ${ }^{[31]}$ It reported that the majority of teachers had poor knowledge on disaster management. Meanwhile their knowledge was improved after teaching program regarding rural disaster management.

In the same line, Mhaske in 2012 found that a planned teaching program on knowledge regarding disaster management among secondary school teachers was very effective in increasing the knowledge of teachers on disaster management. ${ }^{[32]}$

Again, Suresh in 2010 conducted a study to determine the effectiveness of a structured teaching program on knowledge and practices of disaster management among school

Published by Sciedu Press teachers. She revealed that there was gross inadequacy of knowledge on disaster management among school teachers. The teaching program succeeded in achieving significant improvements among school teachers' knowledge and management skills regarding disaster management with highly significant difference in knowledge and practice of school teachers before and after teaching program. ${ }^{[33]}$

In addition, Ganpatraoin 2014 reported that there is inadequate knowledge among school teachers regarding disaster management. He emphasized that teachers must be aware of disaster management in schools, gain knowledge and implement safety practices in school environment. ${ }^{[34]}$ It is noticeable that disaster has significant impact on school children and the facts that confirm safety of them are basic rights of children. Accordingly, there is an urgent need for training program to enhance knowledge and practices of teachers, which help them to manage if an emergency arises.

Regarding disaster management practice of schoolteachers' pre and post intervention, the findings illustrated that the majority of them had inadequate practice. Meanwhile after implementation nearly two thirds of school teachers acquired adequate practice with statistical significant difference pre and post intervention $(p>.000)$.

It was evident that knowledge and practice of school teachers were less than adequate for helping children who are hurt in accidents occurring in schools and for minimizing the impact of the disaster on the school community. Hence, it is mandatory to conduct this training program for all the teachers to improve their management in disaster and emergency situations successfully.

Similarly, a recent study on effectiveness of training manual on disaster management among secondary school teachers at Pune city, Joshi et al. in 2015 reported the effectiveness of training in improving the performance of the schoolteachers. Whereas pre self-express of practice score was 7.05 and posttest self-expressed practice score was 11.93 showing increase by $69.92 \%$, which proved statistically. ${ }^{[35]}$

In accordance to Hegazy et al. who conducted a study in 2015 on impact of a disaster educational program on knowledge and practices of primary school teachers in Cairo, they found that the majority of teachers were unskillful concerning disaster management before the educational program. Meanwhile the majority of them were skillful enough after the educational program implementation, which proved statistically. ${ }^{[22]}$

Riad et al. in 2013 concluded that there are significant deficiencies among majority of schoolteachers regarding disaster management and first aid management. Moreover, there was 
a significant improvement after the program implementation of the knowledge and skills of school teachers regarding first aid, dealing with crisis management and evacuation of students during fire, which proved statistically. ${ }^{[36]}$

Our findings found positive correlation $(p>.000)$ between age, previous training and experience of school teachers and between their knowledge and practice of first aid and disaster management. In addition, it revealed that females were more knowledgeable and skillful than males regarding first aid and disaster management. In addition, the study confirmed positive correlation between knowledge of first aid, practice of first aid and between knowledge of disaster management. Meanwhile, knowledge of disaster management correlates positively with practice of disaster management and knowledge and practice of first aid.

In accordance, Riad et al. in 2013 revealed a positive correlation between age, knowledge, experience and practices regarding first aid and crisis management. As well, knowledge, and practices regarding first aid were positively correlated. ${ }^{[36]}$ Hegazy et al. in 2014 revealed that a statistically significant negative correlation was found between teacher's sex and their total knowledge scores $(p=.01){ }^{[22]}$

Additionally, Ganpatrao in 2014 reported moderate correlation between knowledge and self-expressed practices of secondary school teachers regarding disaster management. ${ }^{[34]}$ Abdella et al. in 2015 proved the association between the teachers' practices improvement and selected demographic variables as their age and years of experiences with posi- tive correlation between teacher's knowledge and practice regarding first aid. ${ }^{[30]}$

In contrary, Mhaske's findings in 2012 revealed that there was no significant association of pre and posttest knowledge scores with demographic variables. ${ }^{[32]}$

\section{Conclusion}

The results illustrated a general lack of information and performance among school teachers regarding disaster and first aid management. However, the training program was effective in enhancing knowledge and practice of disaster and first aid management, which proved statistically. In addition, the study found positive correlation among demographic variables of school teachers' knowledge, practice of first aid and disaster management. In addition, it was found positive correlation among knowledge of first aid, practice of first aid and knowledge of disaster management.

\section{Recommendation}

The study recommended a need for application of first aid and disaster management programs to all school teachers to enhance their knowledge and practice, to protect children and to implement safety practices in school environment.

Further researches needed to assess the impact of such programs on school health safety and child health.

\section{CONFlicts OF INTEREST Disclosure}

The authors declare that there is no conflict of interest.

\section{REFERENCES}

[1] International Council for Science (ICSU). Natural and Humaninduced, Hazards and Disasters in sub-Saharan Africa. 2007. Available from: http://www.icsu.org/icsu-africa/public ations/reports-and-reviews/icsu-roa-science-plan-o n-hazardsdisasters/Doc\%20SP03.1_ICSU\%20ROA\%20Scie nce $\% 20 \mathrm{Plan} \% 20-\% 20$ Hazards $\% 20$ and $\% 20$ Disaster.pdf

[2] UNDP. Disaster Management and Preparedness. UNDP; Nairobi. 2008.

[3] World Health Organization. Risk reduction and emergency preparedness: WHO six year strategies for the health sector and community capacity development. 2007.

[4] Cohen JA, Mannarino AP. Supporting children with traumatic grief: What educators need to know? School Psychology International. 2011; 32(2): 117-131. http://dx.doi.org/10.1177/0143034 311400827

[5] Kumar SD, Kulkarni P, Srinivas N, et al. Perception and Practices Regarding First Aidamong School Teachers in Mysore. Natl J Community Med. 2013; 4(2): 349-352.

[6] Moghadam MN, Shykhoeslami S, Rahimisadeq R, et al. Iranian Nursery School Teachers' Knowledge about Safety Measures in
Earthquakes. Al Ameen J Med Sci. 2012; 5(1): 63-68.

[7] Markenson D, Ferguson J, Chamiedes L. American Heart Association and American Red Cross Guidelines for First Aid. Accessed 12 February 2011. 2010. Available from: http://circ.ahajourna ls.org/cgi/content/full/122/18_suppl_3/S934

[8] Van de VS, Heselmans A, Roex A, et al. Effectiveness of nonresuscitative first aid training in laypersons: a systematic review. Annals of Emergency Medicine. 2009; 54(3): 447-57. PMid:19157654 http: //dx.doi.org/10.1016/j.annemergmed.2008.11.005

[9] Bhatia V, Puri S, Mangat C, et al. An intervention study to strengthen First aid care in school of Chandigarh, India. The Internet Journal of Family Practice. 2011. Available from: http://www . ispub.com/journal/the-internet-journal -of-family-practice/volume-8-number-1/an-intervent ionstudy-to-strengthen-first-aid-care-in-schools-o f-chandigarh-india.html

[10] Sosada K, Zurawinski W, Stepien T, et al. First aid training for teachers. First aid training service Galway Ireland. Available from: http: //www.firstaidi.e./first-aid-training-for-teachers

[11] Zhang C, Zeng N, Lai C. A survey on teachers' mental health after Wenchuan earthquake. Chinese Journal Special Education. 2009; 5: 
46-50. Available from: http://en.cnki.com.cn/Article_en/ cjfdtotal-zdtj200905011.htm

[12] Alexandropoulou M. The effectiveness of first aid health education programs in the community: Critical review (in Greek). Hellenic Journal of Nursing Science (Greek). 2011; 4(4): 53-63.

[13] Inman DD, Bakergem KM, LaRosa A, et al. Evidence-based health promotion programs for schools and communities. American Journal of Preventive Medicine. 2011; 40(2): 207-219. PMid:21238871 http://dx.doi.org/10.1016/j.amepre.2010.10.031

[14] Alexandropoulou M. Evaluating a Health Educational First Aid Program for Special Education School Personnel: a Cluster Randomized Trial. International Journal. 2013; 6(1): 115-126.

[15] Shiwaku K. Comparative study on teacher training for school disaster management in Armenia and Japan. Disaster Prevention and Management. 2014; 23(2): 197-211. http://dx.doi.org/10.11 08/DPM-12-2012-0144

[16] Janice K. Disaster Preparedness In Public Secondary Schools In Githunguri District, Kiambu County, Kenya, Master thesis, Kenyatta University. 2011.

[17] Chen C, Yu K, Chen M. Planning of professional teacher-training program for disaster prevention education and executing efficiency evaluation. Disaster Prevention and Management: An International Journal. 2012; 21(5): 608-623. http://dx.doi .org/10.1108/0 9653561211278734

[18] Central Agency for Statistics and Mobilization. Manual of Egyptian schools. Cairo, Egypt. 2013.

[19] Health Insurance Agency. Accidents Report for School Children, Cairo, Egypt. 2009.

[20] Badary H. Disable schooling affected by the floods. Egypt News. Cairo. Egypt. 2014.

[21] Egyptian A. The Egyptian Coalition for the Rights of the Child: The government's negligence is killing our children in schools. Egypt. 2014.

[22] Hegazy M, Shounoda M, Ismail G. Impact of a Disaster Educational Program on Knowledge and Practices of Teachers among Primary Governmental Schools, Cairo Governorate. Journal of Education and Practice. 2014; 5(29): 175-184.

[23] Abulnour AH. Towards efficient disaster management in Egypt. HBRC Journal. 2014; 10: 117-126. http://dx.doi.org/10.10 $16 / j$.hbrcj . 2013.07.004

[24] Al-Samghan AS, Al-Shahrani FM, Al-shahrani FH. Primary School Teachers' Knowledge about First-Aid, Med. J. Cairo Univ. 2015; 83(1): 541-547.
[25] Abernethy L, Macauley D, Mcnally $\mathrm{O}$, et al. Immediate care of school sport injury. Injury Prevention. 2003; 9: 270-3. http://dx .doi.org/10.1136/ip.9.3.270

[26] Younis JR, El-Abassy A. Primary teachers' first aid management of children's school day accidents: Video-assisted teaching method versus lecture method. Journal of Nursing Education and Practice. 2015; 5(10): 60-69. http://dx.doi.org/10.5430/jnep.v5n10p60

[27] Ali SA, Abu-Elseoud AR, Heybah SM, et al. Implementation of an Educational Training Program In First Aid For Newly Graduated Nursery School Teachers At Zagazig City, Zagazig Journal of Occupational Health and Safety. 2010; 3(1): 29. http: //dx.doi.org/10.4314/zjohs.v3i1.57947

[28] Başer M, Çoban S, Taşci S, et al. Evaluating First Aid knowledge and attitudes of primary school teachers. Journal Emergency Nursing. 2007. 428-432 p. http://dx.doi.org/10.1016/j.jen.2 006.11 .003

[29] Li F, Sheng X, Zhang J, et al. Effects of pediatric first aid training on preschool teachers: a longitudinal cohort study in China. BMC Pediatrics. 2014; 14: 209. PMid:25152013 http://dx.doi.org/1 $0.1186 / 1471-2431-14-209$

[30] Abdella NA, Abu-Elenen NM, Elkazaz RH, et al. Intervention program for the kindergarten teachers about pediatrics first aids. American Journal of Research Communication. 2015; 3(5): 178-194.

[31] Ramya VS. Effectiveness of structured teaching programme on knowledge regarding disaster management among schoolteachers at SRKVB matriculation school, kulashekaram, Tamilnadu. Unpublished master's degree dissertations submitted to MGR University Tamilnadu. 2006.

[32] Mhaske S. Knowledge regarding disaster management among secondary school teachers. Sinhgad E Journal of Nursing. 2012; 2(2): 27-29.

[33] Suresh S. Effectiveness of structured teaching programme on knowledge and practices of disaster management among school teachers. Nightingale Nursing Times. 2010; 6(6): 44-57.

[34] Ganpatrao JS. Knowledge and practices of schoolteacher regarding disaster management. Int J Health Syst Disaster Manage. 2014; 2 : 98-102. http://dx.doi.org/10.4103/2347-9019.139055

[35] Joshi SG, Sawane K, Jabade M. Effectiveness of training manual on disaster management in terms of knowledge and self-expressed practices among secondary school teachers in selected schools of Pune city. International Journal of Science and Research (IJSR). 2015; 4(9): 2093-2096.

[36] Riad NA, Rabea FM, Badawy AI. Capacity Building of Females Governmental Secondary School Teachers in Abha City For Crises Management \& First Aid. Journal of Education and Practice. 2013; 4(23): 33-41. 